\title{
An Eye-Tracking Study of Equivalent Effect in Translation
}

WalKer, CALlum. 2021. An Eye-Tracking Study of Equivalent Effect in Translation: The Reader Experience of Literary Style. London: Palgrave Macmillan.

Reviewed by OBED EBENEZER .S

Though equivalence is considered to be a fundamental concept in Translation Studies, it has also been subjected to numerous debates, disputes, and deliberation. Theorists such as Vinay and Darbelnet, Roman Jakobson, Eugene Nida, J.C. Catford, Juliane House, Werner Koller, and Mona Baker have approached and defined equivalence from different perspectives. The lack of a uniform methodology to determine the extent of this ever-evasive 'sameness' has only served to intensify this debate. However, Walker Callum, in this book, explores the possibility of using eye-tracking as a useful tool to examine the equivalence of 'effect' by studying the cognitive processing of readers reading an ST and a TT.

Translation had earlier been considered purely as a linguistic exercise. Of late, perhaps due to the influence of closely allied disciplines, TS has been concerned with culture, gender, and socio-political issues that arise in translation. The stylistic aspects of literary translation have largely been overlooked- in fact, the number of full-length books solely dedicated to discussing 'style' in Translation is very limited. However, it must also be kept in mind that the notion of the 'effect' of stylistic devices on the reader has largely been hypothetical and based on assumptions. With the adoption of empirical approaches into TS, and especially in TPR (translation process research), it has been possible to gain some insights into the cognitive processing during tasks. Even so, such approaches within TS have been limited to TPR and AVT (audio-visual translation). Walker extends the possibility of using eyetracking to study cognitive effects in the reception of translated 
texts. This is achieved by comparing the eye movements of readers reading the ST with those reading the TT.

After laying down a general introduction of the study in Chapter 1, including a brief overview of the methodology adopted, the objectives of the study, and the overall structure of the book, the author then proceeds to discuss in Chapter 2, the Cognitive turn in TS. James S. Holmes, in his foundational paper, "The name and nature of translation studies" (1972), had characterised descriptive translation studies (DTS) into three kinds: product-oriented, function-oriented, and processoriented DTS. Cognitive approaches in TS, however, have been primarily limited to studying the process of translation, while the product or reception of translation has largely been overlooked. Therefore, the fact that there is an evident lack of empirical data regarding stylistic devices and cognitive experience across both ST and TT forms the research gap that the author seeks to address.

Chapter 3 moves on to a discussion of literature and stylistics, by starting off on Authorial Intent as opposed to Reader Response criticism. In both instances, the text was displaced. Stanley Fish, in his later works, held the view that authors employ certain linguistic devices to guide a reader to apply a set of interpretive strategies so as to generate meaning (1980: 14). This then leads to Umberto Eco's concept of 'open' and 'closed' texts, where the reader actively takes part in the process of interpretation in the former, and where the text pulls the reader along in a predefined manner in the latter (1984: 4,8). Walker then reconceptualises Eco's notion and situates it at the stage of the reading experience- the phase between the text and its interpretation.

The principles of reading behaviour with respect to eye movements are laid down in Chapter 4. Starting with the history of eye-tracking, the various eye movements, and terms 
used in eye tracking, the author proceeds to discuss the various models of reading. Relevant findings from the Empirical Study of Literature (ESL) with regard to foregrounding and the capture of the reader's attention through lexical and/or syntactic devices are described to reveal the link between visual attention and processing effort.

In Chapter 5, the principles of stylistics and the observations from ESL and eye tracking are brought together to apply to translation. The notion of equivalence in translation is taken up. Though equivalence has largely been dismissed as being presumptive, Walker opines that the cognitive element in the phenomenology of reading has been ignored. Thus, the concept of cognitive equivalence, which is the ratio of the cognitive effort while reading the ST to that of the TT, is placed forward, not taking into account the accuracy of the translation.

The principles of the experimental method adopted for the study, the statistical approach for data interpretation, and also the experimental setup, is described in Chapter 6. The null hypothesis, where the variables between the two groups (one reading the ST and the other the TT) are equal, is indicative of cognitive equivalence $\left[\mathrm{H}_{0}: \mathrm{ST} \approx \mathrm{TT}\right]$ (Walker 2021: 217). Thus, in this scenario, an ST and its corresponding TT display highly similar cognitive processes as is revealed through eye movements. The first alternate hypothesis, indicated by a greater cognitive load in the ST than the TT, suggests that cognitive equivalence has not been achieved $\left[\mathrm{H}_{1}: \mathrm{ST}>\mathrm{TT}\right]$ (2021: 218). The second alternate hypothesis, indicated by a greater cognitive load in the TT than the ST, suggests that cognitive equivalence has not been achieved due to overcompensation in translating stylistic devices $\left[\mathrm{H}_{2}: \mathrm{ST}<\mathrm{TT}\right]$ (2021: 219). 
Moving on to the experimental design, eye-tracking measurements including "first fixation duration (FFD), gaze duration (GD), total fixation duration (TFD), fixation count (FC)...pupil dilation... saccade- or regression..." (2021: 223) are taken as the dependent variables. Extracts from Raymond Queneau's Zazie dans le métro (1959), its English translation, Zazie in the Metro (1960) by Barbara Wright, and a modified version of the English text have been taken as independent variables. 45 participants, comprising of 17 French native speakers and 28 English Native speakers made up the sample population. A $300 \mathrm{~Hz}$ eye tracker was used for capturing eye movements.

Chapter 7 proceeds to discuss the results obtained in the study. The relevant data from each group is plotted. Since the data collected in an eye-tracking study will be extremely large, only the data corresponding to certain stimuli is presented. The findings suggest that this kind of mixed-method approach has significant merit and that the empirical data corresponds to the predictions anticipated in stylistic analyses. The author suggests that this is merely a handful, and that further analysis of the data is possible, and that such an approach holds "boundless potential" (2021: 359) for further exploration.

In Chapter 8, the concluding chapter of this book, certain findings, and their implications in stylistics are discussed. Literary theory and criticism, with regard to the effect of stylistic devices on cognition, has largely been subjective and speculative. By using an eye tracker, objective data can be obtained. Though there are individual and between-group differences in the cognitive processing and experience, it is seen that heightened style results in higher fixation durations, and also exhibits a more heterogeneous reading experience. This means that readers experience a wide range of cognitive levels while processing such texts. On the other hand, a prosaic 
An Eye-Tracking Study of Equivalent Effect in Translation

text using high-frequency or predictable words exhibits a homogenous experience across readers.

The chapter (and the book) concludes by discussing certain criteria that could be modified to increase the validity and feasibility of this study, and also looks at avenues for future research in this area.

\section{References}

BAKER, MONA. 1992. In Other Words: A Coursebook on Translation. London: Routledge.

CATFORD, JOHN C. 1965. A Linguistic Theory of Translation: An Essay on Applied Linguistics. London: Oxford University Press.

ECO, UMBERTO. 1984. The Role of the Reader: Explorations in the Semiotics of Texts. Bloomington: Indiana University Press.

Fish, Stanley. 1980. Is There a Text in This Class? The Authority of Interpretive Communities. Cambridge, MA: Harvard University Press.

Holmes, James S. 2001 [1972]. The Name and Nature of Translation Studies. In Venuti, Lawrence (ed), The Translation Studies Reader. London: Routledge. 172-185. House, Juliane. 1977. A Model for Translation Quality Assessment. Tübingen: Gunter Narr.

JAKOBSON, R. 1959 [2000]. On Linguistic Aspects of Translation. In Venuti, Lawrence (ed.), The Translation Studies Reader. London: Routledge. 113-118.

KOLLER, W. $1979 . \quad$ Einführung in die Übersetzungswissenschaft. Heidelberg: Quelle and Meyer. NidA, EugenE A. 1964. Towards a Science of Translating. Leiden: E. J. Brill.

Queneau, RAYMOND. 1959. Zazie dans le métro. Paris: Gallimard. 
QuenEAU, RAYMOND. 1960. Zazie in the Metro (Barbara Wright, Trans.). London: Penguin

VINAY, J. P. \& DARBELnET, J. 1958 [1995]. Comparative Stylistics of French and English: A Methodology for Translation (Sager, J. C. \& Hamel, M. J., Trans.). Amsterdam \& Philadephia: John Benjamins.

WalKer, Callum. 2021. An Eye-Tracking Study of Equivalent Effect in Translation: The Reader Experience of Literary Style. London: Palgrave Macmillan.

\section{Cite This Work:}

EBENEZER .S, OBED. An Eye-Tracking Study of Equivalent Effect in Translation. Review of An Eye-Tracking Study of Equivalent Effect in Translation: The Reader Experience of Literary Style by Callum Walker. Translation Today, Vol. 15(1). 254-259.

DOI:10.46623/tt/2021.15.1.br2 